\title{
Experimental infection of rock pigeons (Columba livia) with three West Nile virus lineage 1 strains isolated in Italy between 2009 and 2012
}

\author{
M. SPEDICATO, I. CARMINE, A. L. BELLACICCO, G. MARRUCHELLA, \\ V. MARINI, M. PISCIELLA, G. DI FRANCESCO, A. LORUSSO*, F. MONACO \\ AND G. SAVINI
}

OIE Reference Laboratory for West Nile Fever, Istituto Zooprofilattico Sperimentale dell'Abruzzo e Molise, Teramo, Italy

Received 9 April 2015; Final revision 7 October 2015; Accepted 8 October 2015; first published online 23 October 2015

\section{SUMMARY}

West Nile virus (WNV) circulation dynamics in the context of the urban environment is not yet elucidated. In this perspective, three groups of eight rock pigeons (Columbia livia) were inoculated with three WNV lineage 1 strains isolated in Italy between 2009 and 2012. The pigeons did not develop any clinical signs consistent with WNV acute infection. All animals seroconverted and shed virus up to 15 days post-infection by the oral or cloacal routes. In all infected groups viraemia lasted for 4 days post-infection. No WNV-specific gross or histological lesions were found in infected birds compared to control birds and immunohistochemistry remained constantly negative from all tissues. The reservoir competence index was also assessed and it ranged between $0 \cdot 11$ and $0 \cdot 14$. This study demonstrates that pigeons are competent reservoir hosts for Italian WNV lineage 1 circulating strains thus potentially posing a risk to the public health system.

Key words: Pathology, reservoir competence index (RCI), rock pigeon, viraemia, West Nile virus.

\section{INTRODUCTION}

West Nile virus (WNV) is an enveloped singlestranded, positive-sense RNA virus (family Flaviviridae, genus Flavivirus) isolated for the first time in the West Nile district of Uganda in 1937 [1] and it is the aetiological agent of West Nile fever, an important zoonosis (reviewed in [2]). WNV belongs to the Japanese encephalitis serocomplex, which includes several human and animal pathogens such as Japanese encephalitis virus, Murray Valley encephalitis virus, St Louis encephalitis virus and Usutu virus

\footnotetext{
* Author for correspondence: Dr A. Lorusso, OIE Reference Laboratory for West Nile Fever, Istituto Zooprofilattico Sperimentale dell'Abruzzo e Molise, Teramo, Italy. (Email: a.lorusso@izs.it)
}

(USUV) [3, 4]. Based upon the genomic relatedness of circulating strains up to nine WNV lineages have been proposed so far, and, among these, lineages 1 and 2 (L1 and L2) are the most widespread [5-10]. Very recently, a novel WNV lineage classification has been proposed [11]. WNV circulation relies on an enzootic cycle involving mosquitoes (mainly Culex spp.) as vectors and birds as reservoir and amplifying hosts [12-15]. The cycle can be further divided into a rural (or sylvatic) cycle between wild water birds and ornithophilic mosquitoes, and a so-called 'urban' cycle involving synanthropic birds and mosquitoes. Humans and horses may become infected from spillover of the enzootic cycle. However, they are considered incidental hosts as they develop a lowmagnitude viraemia of short duration [16]. 
Since the first outbreak in 1998 and before the emergence and spread of L2, WNV infections in Italy were sustained by strains belonging to L1 [1721]. WNV has been isolated from both sylvatic and urban avian species belonging to different orders including Passeriformes, Ciconiformes, Falconiformes, Anseriformes, Columbiformes, and Strigiformes.

Once infected, most of birds are usually asymptomatic; however, depending on the susceptibility of the species and the strain involved, mild to severe signs can develop, such as inappetence, weight loss, lethargy, recumbency, abnormal posture, ataxia and anisocoria. The most susceptible avian species (e.g. corvids) can succumb to disease [2, 10, 22]. The rock pigeon (Columba livia) is a synanthropic bird that lives in urban and rural areas throughout the world [23]. Therefore, this bird can act as a link between the rural and urban cycles of WNV, posing a serious threat to humans by contributing to the spread of the infection.

In this study we aimed at evaluating if rock pigeons are competent reservoir hosts for WNV by reporting clinical status, viraemia, viral shedding, humoral response, tissue tropism and macroscopic and microscopic lesions from experimentally infected pigeons with low-passaged WNV L1 strains isolated from wild birds in Italy between 2009 and 2012 .

\section{MATERIALS AND METHODS}

\section{Ethics}

All procedures on animals were performed regarding the European and Italian laws on the use of animals for experimental purposes (Italian Decreto Legislativo $116 / 92$ on the protection of animals for experimental and other scientific purposes and Directive 2010/63/ EU on the protection of animals used for scientific purposes) and approved by the Animal Welfare Committee of the Istituto Zooprofilattico Sperimentale dell'Abruzzo e Molise.

\section{Animals and study preparation}

Twenty-seven $(n=27)$ healthy rock pigeons aged between 4 and 5 years were purchased from a commercial breeding facility and randomly housed in stainless-steel cages placed in three different Biosafety Level-3 Laboratory (BSL-3) containment units (three cages per unit) at the OIE Reference Laboratory for West Nile Fever of Teramo. Each unit was furnished with a HEPA-filtered negative air system. The birds were ringed with aluminium rings of different colour and uniquely identified according to cage number and ring colour. Birds were allowed to acclimatize for 1 week before infection. Furthermore, they were checked at least once a day in order to detect any signs of illness or stress potentially interfering with the experimental study. During the entire length of the study, birds were allowed to feed ad libitum and they had free access to fresh water. Just prior the infection (T0), blood was collected from all animals in EDTA tubes and the recovered plasma fraction was screened in order to confirm the absence of specific WNV/USUV antibodies by serum neutralization test and the absence of active WNV/USUV viraemia by quantitative reverse transcriptasepolymerase chain reaction (qRT-PCR). At the same time, cloacal and oropharyngeal swabs were taken and screened by qRT-PCR.

\section{Viruses}

Birds were randomly divided in four treatment groups: group A consisting of eight birds administered with WNV 12010/09 strain isolated in 2009 from the brain of a dead magpie (Pica pica); group B consisting of eight birds administered with WNV 21412/11 strain isolated in 2011 from the brain of an euthanized WNV-symptomatic little owl (Athene noctua); group $\mathrm{C}$ consisting of eight birds administered with WNV $20652 / 12$ strain isolated in 2012 from the brain of a dead magpie; and group K (control group) consisting of three mock-administered animals. The magpies were found dead and collected during the passive surveillance activities implemented in the Italian surveillance programme for West Nile fever.

Phylogenetically, the three strains were shown to belong to the Western Mediterranean subclade of WNV L1. Strains 12010/09 and 21412/11 bear the highest nucleotide identity (99\%) with strain Italy/ 2008/J- 242853 (JF 719065 [24]) whereas strain 20 $652 / 2012$ bears the highest nucleotide identity (99\%) with strain Italy/2011/Livenza (JQ 928174 [25]). All strains were isolated straight from the infected tissues of dead birds according to OIE recommendations and passaged in total four times on cells before administration. Cell passage 4 on Vero cells was used for administration in pigeons. Complete nucleotide sequences of challenged viruses were obtained by standard procedures employing total RNA purified from infected Vero cells. Strains 12010 and 20652 showed a proline 
residue at position 249 of the NS3 protein whereas strain 21412 showed a threonine residue at the same position. Viruses were titrated in 96-well plates on Vero cells and diluted in Eagle's minimum essential medium to a final concentration of $10^{6} \mathrm{TCID}_{50} / \mathrm{ml}$ which was used for challenge.

\section{Study design}

Birds were administered subcutaneously in the inguinal region with $1 \mathrm{ml}$ corresponding virus. Control birds were sham inoculated with $1 \mathrm{ml}$ sterile medium. Birds were observed daily for detection of any clinical sign consistent with acute infection (body posture, behaviour and neurological symptoms). Starting from day post-infection 1 (T1) the treatment and control groups were randomly divided into two cohorts, each of which was sampled on alternate days (i.e. $1,3,5,7,14$ or $2,4,6,8,15$ days post-inoculation) for 22 days in total. Furthermore, venepuncture was performed alternatively on the right and left brachial veins to decrease stress and to avoid haematomas in the bleeding region. Once collected, the blood was immediately placed into EDTA tubes. Cloacal and oral cavities were sampled by cotton-tipped swabs. Blood samples were centrifuged at $1300 \mathrm{~g}$ for $10 \mathrm{~min}$. The resulting plasma was divided in two aliquots for serological and molecular investigations. Regarding swabs, these were immediately eluted in dedicated tubes containing PBS, antibiotics and antimycotics, vortexed, divided in two aliquots and stored at $-80^{\circ} \mathrm{C}$ until RNA extraction.

All animals were also weighed with a digital scale prior to infection (T0) and at each sampling day.

\section{Tissue tropism}

Birds were euthanized by cervical dislocation and necropsy was performed within $1 \mathrm{~h}$. Birds in group A were killed at 27 days post-infection (T27), group B at T30 and group $\mathrm{C}$ at T35. One control bird was necropsied with each experimental group.

At necropsy, gross findings were recorded. Spleen, kidney, brain, cerebellum, lung, liver, small intestine and heart were collected. Collected organs were divided in two aliquots: one was fixed in 10\% neutral buffered formalin and the other was refrigerated in dedicated tubes until RNA extraction. Tissue homogenates were inoculated into confluent monolayers of C6/36 (Aedes albopictus) and Vero cell lines from organs that were positive by qRT-PCR according to OIE recommendations.

\section{Histology and immunohistochemistry (IHC)}

Tissue samples were fixed in 10\% neutral buffered formalin for $24 \mathrm{~h}$ and embedded in paraffin wax. Subsequently, tissue blocks were sectioned at a thickness of $5 \mu \mathrm{m}$, stained with haematoxylin and eosin (HE) and examined microscopically. Formalin-fixed and paraffin-embedded sections of collected tissues were processed for IHC as previously described. IHC was performed using rabbit polyclonal antibody (ab22 070, Abcam, UK) diluted 1:250. Briefly, tissue sections were heat-treated for antigen retrieval $\left(121^{\circ} \mathrm{C}\right.$ for $8 \mathrm{~min}$ in $0.01 \mathrm{~m}$ citrate buffer, $\mathrm{pH} 6.0$ ) and immune reactions were revealed using a peroxidase technique (Envision Plus kit, Denmark).

\section{One-step real-time RT-PCR assays, qRT-PCRs}

Total RNA was automatically extracted from $100 \mu \mathrm{l}$ of each plasma sample, from swabs' supernatant and organ homogenates, using the BioSprint 96 OneFor-All Vet kit (Qiagen, Germany), following the manufacturer's instructions.

RNA extracted from plasma samples at T0 were initially screened by qRT-PCR [26] in order to exclude active WNV viraemia by WNV L1 or L2. Following virus administration, a qRT-PCR [27] targeting the envelope encoding gene of WNV L1, was used to screen all biological samples collected in the study including plasma samples, and swabs' supernatant and organ homogenates.

\section{Serum neutralization test}

Plasma samples were tested for the presence of WNV antibodies by serum neutralization test as described previously by our group [28].

\section{Virus isolation}

Isolation was attempted from qRT-PCR-positive plasma swab samples and organs as previously described. PCR-positive plasma and swabs' supernatants were also titrated on Vero cells by end-point dilution and titre expressed as 50\% tissue culture infectious dose $\left(\mathrm{TCID}_{50}\right.$ ) [29]. As most of the experiments with flaviviruses refer to plaque-forming units (p.f.u.) it is important to point out that titration 
experiments performed in our laboratory with the same samples and in the same conditions, showed that both titration methods, end-point dilution and plaque assay on Vero cells had the same titres, thus with $\mathrm{TCID}_{50} /$ p.f.u. ratio $=1$, whereas in general 1 TCID $_{50}$ is supposed to be equivalent to approximately $0 \cdot 7$ p.f.u. [30].

\section{Reservoir competence index (RCI)}

The RCI is an estimation of the number of infectious vectors resulting after a bloodmeal on a specific viraemic bird species. It is calculated using the formula $C=S \times I \times D$, where $S$ represents susceptibility, i.e. the proportion of birds infected as a result of exposure; $I$ represents infectiousness, i.e. the proportion of exposed vectors that become infectious per day; and $D$ is the duration of infectiousness, i.e. the number of days a bird maintains an infectious viraemia [31]. The RCI was calculated for each group of pigeons. In line with most studies, we considered as infectious a viraemia $\geqslant 10^{5} \mathrm{TCID}_{50} / \mathrm{ml}$, whereas lower values were considered as zero. Infectiousness percentage was calculated as $I=0.1349 \times \log _{10}$ (viraemia) 0.6235 as described previously [32]. In calculating the mean RCI for each group, we considered only those birds with an infectious level of viraemia.

\section{Statistical analysis}

Differences between groups were analysed using oneway ANOVA (Graphpad Instat Software, USA), with Tukey-Kramer's post-test. A probability of $P<0.05$ was set as the significance level.

\section{RESULTS}

At T0, all animals tested negative for specific WNV and USUV antibodies and for WNV/USUV RNA. Residual challenge virus solutions were back-titrated and results were as follow: strain 12010/09, $10^{5 \cdot 89}$ $\mathrm{TCID}_{50} / \mathrm{ml}$; strain $21412 / 11,10^{6 \cdot 39} \mathrm{TCID}_{50} / \mathrm{ml} ; 20$ $652 / 12,10^{5.99} \mathrm{TCID}_{50} / \mathrm{ml}$.

Sham-inoculated animals tested serologically and virologically negative for the entire experiment. Mean body weight in birds belonging to the same group did not show any significant variation over time (data not shown). Statistical comparisons between infected and control birds was unfortunately not possible as control pigeons were very limited in number. None of the birds developed clinical signs consistent with acute infection, and all birds were euthanized according to the experimental setting.

\section{Tissue tropism}

Birds of groups A, B and C were euthanized and necropsied at T27, T30 and T35, respectively. Only kidneys and spleens tested positive for WNV RNA; i.e. four spleens and one kidney from group A and three spleens and two kidneys from groups B and C. However, attempts to isolate WNV were unsuccessful from all tissue samples.

\section{Histology and IHC}

Multiple foci of interstitial hepatitis and nephritis were observed in WNV-infected (24/24) and healthy control (3/3) pigeons. Inflammatory infiltrates consisted of lymphocytes and plasma cells, which sometimes appeared as follicle-like structures. Hepatic granulomas, with a necrotic core surrounded by multinucleated giant cells, were also occasionally seen.

Splenic lympho-follicular hyperplasia was observed in WNV-infected (18/24) and healthy control (1/3) pigeons (Fig. 1 $a, b$ ). Small foci of myocarditis (Fig. 2), mainly characterized by lymphocytes infiltrating the interstitial connective tissue, were detected in 4/24 WNV-infected animals (one in group A and three in group C). Very mild meningitis was detected in $1 / 24 \mathrm{WNV}$-infected pigeons and $1 / 3$ controls. All tissues from infected and control animals were negative by IHC.

\section{Immune response}

Seroconversion was observed by $\mathrm{T} 5$ in one bird in group A (1:40), all birds in group B (mean 1:22.5) and three birds from group C (mean 1:8·75). By T7 all animals developed neutralizing antibodies (Fig. 3). The highest mean peak of antibody titre occurred at T7 in groups A and B (mean 1:202.5 and $1: 80$, respectively) and at $\mathrm{T} 8$ in group $\mathrm{C}$ (mean 1:65). A bird in group A showed the highest titre (1:640). Hereafter, antibody titres declined in all groups.

\section{Viral shedding}

Shedding dynamics from the cloacal and oral routes are depicted in Fig $4(a, b)$. In groups A and C, 7/8 
(a)

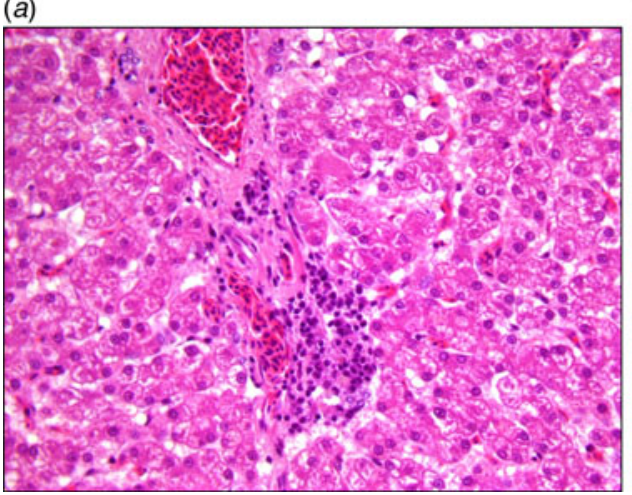

(b)

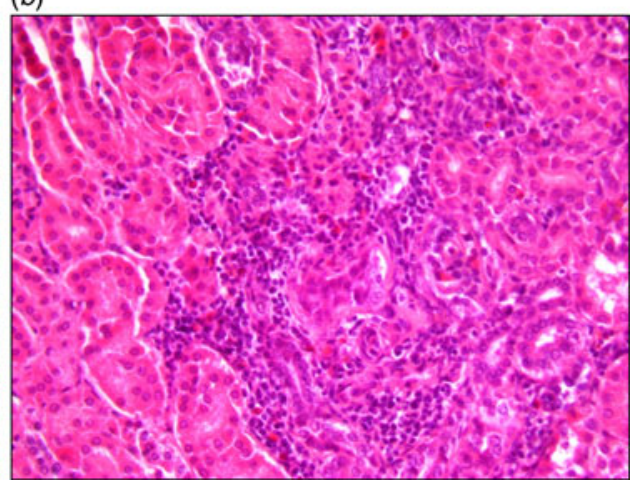

Fig. 1. Splenic lympho-follicular hyperplasia observed in (a) WNV-infected and (b) sham-inoculated pigeons.

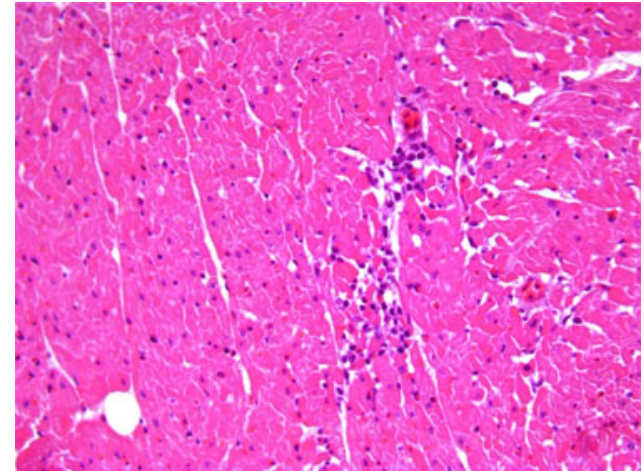

Fig. 2. Foci of myocarditis characterized by lymphocytes infiltrating the interstitial connective tissue detected in 4/24 WNV-infected animals (one in group A and three in group C).

$(87 \cdot 5 \%)$ birds had detectable virus in cloacal swabs, while in group B 6/8 (75\%) birds had detectable virus.

The earliest viral shedding by the cloacal route was observed at $\mathrm{T} 1$ in one bird in group $\mathrm{C}$, while in groups $\mathrm{A}$ and $\mathrm{B}$ it was first observed at $\mathrm{T} 3$ in three and two animals, respectively. In group $\mathrm{A}$, cloacal shedding lasted until $\mathrm{T} 8$; whereas in groups $\mathrm{B}$ and $\mathrm{C}$, it was observed until T12 (Fig. 4a).

Regarding oral shedding (Fig. 4b), in groups A and $\mathrm{C}$, five $(62.5 \%)$ and six $(75 \%)$ birds, respectively, had detectable virus in oral swabs. Oral shedding was first detected at $\mathrm{T} 2$ in groups $\mathrm{A}$ and $\mathrm{C}$, at $\mathrm{T} 3$ in group B. Overall, length of oral shedding was lower compared to cloacal shedding as it was finished at T6. However, intermittent shedding was observed at later time points. Straight titration was attempted from qRT-PCR-positive swab samples. At T2, one oral swab from group A had a titre of $10^{2 \cdot 1}$ $\mathrm{TCID}_{50} / \mathrm{ml}$; from the same group, one oral swab at $\mathrm{T} 3 \mathrm{had}$ the same titre of $10^{2 \cdot 1} \mathrm{TCID}_{50} / \mathrm{ml}$. At T4, virus was isolated from two cloacal swabs of group $\mathrm{C}$, both with a titre of $10^{2 \cdot 1} \mathrm{TCID}_{50} / \mathrm{ml}$.

\section{Viraemia and RCI}

qRT-PCR-positive plasma samples were detected starting at T1. RNA in the blood lasted up to T5 in group $\mathrm{A}, \mathrm{T} 6$ in group $\mathrm{C}$ and $\mathrm{T} 7$ in group $\mathrm{B}$ (Fig. 5a). Regarding sample titration, WNV was isolated from all qRT-PCR-positive plasma samples collected at $\mathrm{T} 1$ and $\mathrm{T} 2$ from all groups, at $\mathrm{T} 3$ and T4 in all animals of groups B and C, and in 3/4 animals of group A (Fig. 5b).

In all infected groups viraemia lasted until T4. Mean viraemia titre ranged from 1.99 to 5.39 $\mathrm{TCID}_{50} / \mathrm{ml}$. At $\mathrm{T} 1$, the viral titre was significantly higher in group B compared to groups A and C $(P<0 \cdot 05)$.

Putative infectious viraemia $\left(\geqslant 10^{5} \mathrm{TCID}_{50} / \mathrm{ml}\right)$ was found in three birds in group $\mathrm{A}$ and five birds in groups $\mathrm{B}$ and $\mathrm{C}$, the infection lasted for 2 days. RCIs were $0 \cdot 14$ in group A, $0 \cdot 11$ in group B and $0 \cdot 12$ in group $\mathrm{C}$.

\section{DISCUSSION AND CONCLUSIONS}

Within the activities of the Italian surveillance programme for West Nile fever implemented by the Ministry of Health, infection by WNV was demonstrated in many species of birds belonging to several avian families including carrion crows (Corvus corone cornix), magpies (Pica pica), goshawks (Accipiter gentilis), skylarks (Alauda arvensis) and one red-breasted goose (Branta ruficollis) (Italian bulletins on West Nile Disease 2008-2014: http://sorveglianza.izs.it/ emergenze/west_nile/emergenze.html). 


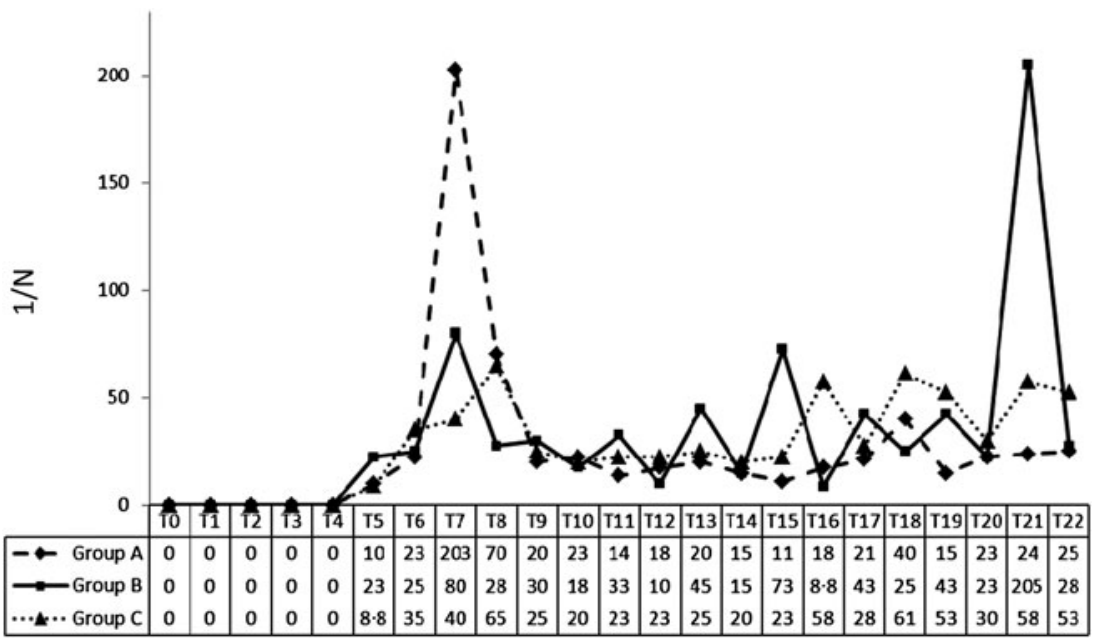

Fig. 3. Mean neutralizing antibody titres in experimentally infected pigeons as obtained by virus neutralization. $x$ axis: days post-infection; y axis: reciprocal of the maximum dilution $(N)$ able to inhibit the cytopathic effect on cell monolayers.
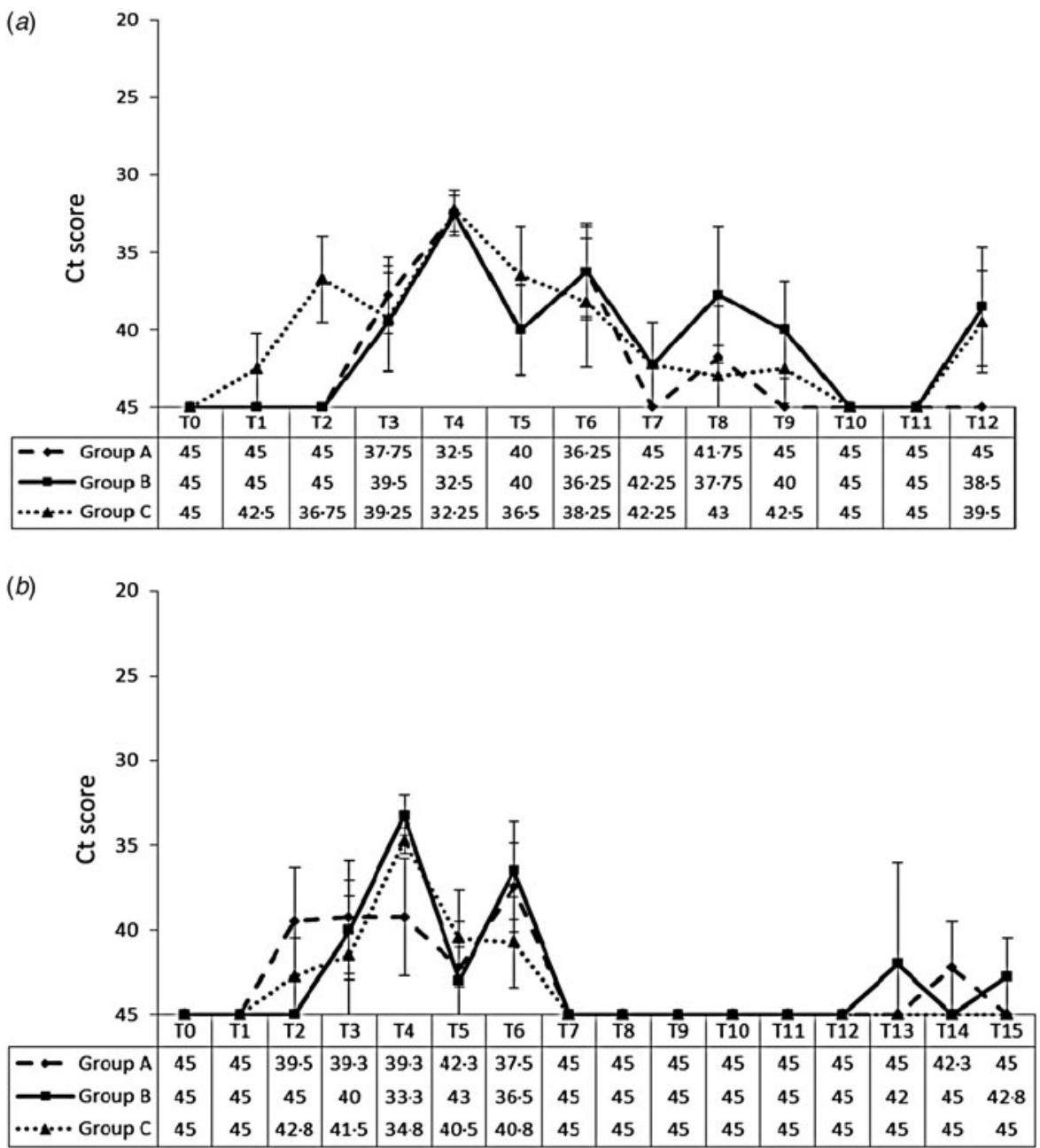

Fig. 4. (a) Cloacal and (b) oral shedding of WNV. Mean $C_{t}$ values ( \pm s.E.M.) for cloacal swabs of experimentally infected rock pigeons, as obtained by real-time $\mathrm{qRT}$-PCR. $\mathrm{x}$ axis: days post-infection; $\mathrm{y}$ axis: mean $\mathrm{C}_{\mathrm{t}}$ score. 

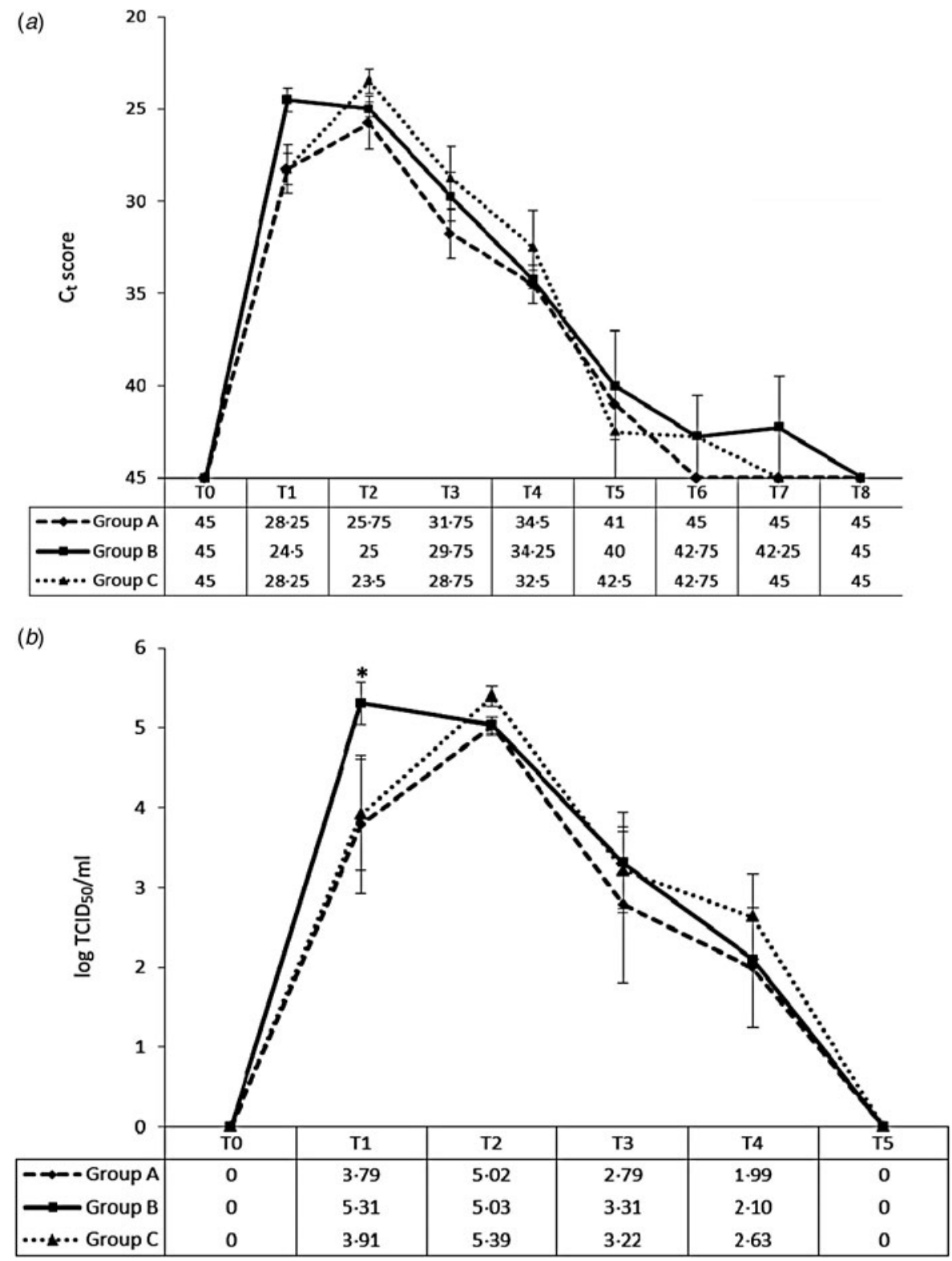

Fig. 5. (a) Plasma samples. Mean $C_{t}$ values ( \pm s.E.M.) as obtained by real-time qRT-PCR. $x$ axis: days post-infection; y axis: mean $\mathrm{C}_{\mathrm{t}}$ score. (b) Mean viral titres ( \pm s.E.M.) as obtained by the Reed \& Muench method. $\mathrm{x}$ axis: days post-infection; y axis: mean $\log _{10} \mathrm{TCID}_{50} / \mathrm{ml}$. The asterisk (*) denotes statistically significant.

However, to the best of our knowledge, no detailed study aimed at evaluation of the role of the rock pigeon (Columba livia) as a reservoir for currently circulating Italian WNV strains has been performed.

Rock pigeon is the most abundant urban avian species that has colonized both urban and rural areas throughout the world. In Italy rock pigeons are copious in public parks and squares, farm lands, outdoor dining places, agricultural environments, drinkingwater reservoirs and rocky cliffs where they usually nest [33-35]. Given the ecology and the extreme adaptability of pigeons to different environments, they may represent a link between urban and rural ecosystems. Particularly in northern Italian wetlands, WNV is endemic within the wild avian species as demonstrated by recent studies (e.g. [36]).

Moreover, field and experimental studies have demonstrated that the rock pigeon has high WNV seroprevalence rates in endemic areas and can reproduce significant levels of viraemia [37, 38]. With this perspective, the rock pigeon experimental model was adopted here in order to gain novel insights into the role of this species in the WNV circulation milieu. Pigeons were administered with three different WNV 
strains isolated in Italy between 2009 and 2012. All viruses were shown to belong to the Western Mediterranean subclade of WNV L1 and are representative of L1 strains that have been actively circulating in Italy in that given time frame.

In this study, pigeons were shown to be susceptible to WNV infection as clearly demonstrated by seroconversion. However, they did not show any sign of WNV acute infection even in the presence of viraemia of high magnitude.

Generally, birds infected with WNV show a wide range of clinical signs [10]. Severe outcomes of disease and high mortality rates have indeed been described in several avian species including domestic geese and storks in Israel, and American crows (Corvus brachyrhyncos) in the United States [39, 40]. Interestingly, in the present study one group of pigeons was inoculated with strain $21412 / 11$ that has been isolated from a little owl with encephalitis. However, when administered to pigeons, this strain did not cause any clinical signs consistent with acute encephalitis. The only significant hallmark of this strain was a higher viral titre $(P<$ $0.05)$ in the plasma samples used to obtain its viraemic curve in pigeons. Whether this phenomenon depends on diverse host susceptibility or on the fact that the administered strain was passaged in vitro before challenge, is hard to say. Straightforwardly, the fact that pigeons did not develop any sign of WNV-related disease is not a novel finding. Indeed, similar results were obtained by Panella et al. [41] in Eurasian-collared doves (Streptopelia decaocto), a Columbiformes species closely related to rock pigeons. In that study none of the birds, even those inoculated with the highly-virulent NY99 strain, showed any clinical signs consistent with WNV acute infection. Comparable results were also achieved in 2003 by Komar and colleagues during an experimental infection with rock pigeons [39]. However with respect to this latter study, the magnitude of viraemia in pigeons infected during our experimental setting is slightly lower. Generally, WNV dynamics of infection in the avian host may depend on several factors related to challenge virus (strain, lineage, wild type or not), to inoculation method (route, syringe or mosquito inoculation, dose) and to host factors (species, age, immune status) [42], thus particular care should be exercised when comparing results from different experimental settings.

Indeed, it should be noted that Komar et al. [39] analogously to Panella et al. [41] employed for challenge the highly virulent NY99 WNV strain responsible for high mortality rates in American crows, and that pigeons were exposed to 5-15 WNV-infected mosquitoes by holding their breast skin against a screened carton containing the infected mosquitoes. It is known that mosquitoes' saliva can influence WNV pathogenesis, increasing the plasma viral titres compared to animals challenged by syringe inoculation despite the route of infection [43-45]. The role of the saliva has been demonstrated for multiple species of mosquitoes of the genera Aedes and Culex and it is thought to be due to the ability of the saliva to modulate skin-resident immune cells (reviewed in [2]).

Overall, in this study most of the birds reached levels of viraemia that have been previously described to be important for WNV transmission [32, 37, 39, 46] and according to RCI values, pigeons can be considered as competent reservoir hosts for the WNV L1 strains that have been circulating in Italy between 2009 and 2012.

Similar RCI values were obtained by Del Amo et al. [47] in house sparrows infected with WNV strains isolated in Italy in 2008 and 2009, including strain Italy/2008/J-242 853 which shares 99\% nucleotide identity with strains $12010 / 09$ and 21412/11 used in this study. House sparrows were indeed eventually demonstrated to be a competent reservoir host for WNV.

Conversely, RCI values obtained in our study are much lower than those obtained in other studies from highly competent species such as blue jay and American crows. However, considering that some species of mosquitoes, including Culex pipiens (the main vector of WNV in Italy) may amplify the virus after a bloodmeal from a bird host with a lower level of viraemia [48] it can be speculated that RCI values alone are too simplistic, and many other factors should be taken into account in order to assess the role of a given host species for transmission. Predation and carrion feeding for instance could have important implications in the case of pigeons. Thus, in field conditions, the role of pigeons may be more relevant, also taking into account the large number of pigeons, their high distribution and their close contact with humans. Nonetheless, the duration of infectious viraemia described in our study ( 2 days) was slightly shorter than those obtained in birds infected with other WNV strains that have been circulating in the Mediterranean basin. Indeed, Sotelo et al. [49] demonstrated a 4-day viraemia in a red-legged partridge inoculated with Spanish and a Moroccan isolates of WNV whereas and Del Amo et al. [47] reported a viraemia of 3 days in house sparrows inoculated with Italian WNV L1 strains. 
Pigeons were also showed to shed virus through the cloacal and oropharyngeal routes up to 15 days postinfection. However, attempts to isolate the infectious virus from cloacal and oral specimens were possible only from few samples and at a relatively low titre. The shedding period is slightly longer with respect to results obtained in other studies [47, 48].

Viral shedding through the oral and cloacal routes may have an epidemiological role in WNV transmission. Several studies have demonstrated that contact transmission of WNV may occur in birds $[2,10]$, hence oral transmission may be important, particularly in crowded groups as pigeons commonly live. However, as far as we know, pigeons are not known to be susceptible to oral transmission of $\mathrm{WNV}$, thus this issue warrants further investigation.

Oral transmission may pose serious concerns for humans as well, especially in those categories of workers dealing with birds such as veterinarians, biologists, laboratory staff and bird breeders. However, as demonstrated by the results of this study, viral oral shedding is of minor relevance. As for gross and histological lesions, foci of mild lymphocytic myocarditis were detected in four infected animals, while lesions in other organs were reported in both infected and control animals. Three out of four pigeons showing myocarditis were from group C. Birds of group $\mathrm{C}$ were euthanized 8 and 5 days later, respectively, compared to birds of groups A and B. Reasonably, myocarditis may represent a lesion occurring at the later stage of infection.

WNV antigens were not revealed by IHC probably because at the time of necropsy, clearance of infectious WNV was already accomplished by the immune system.

This study has some limitations. First, pigeons were not sacrificed during the viraemic phase of infection in order to clearly detect WNV in the organs. However, the main purpose of the study was to characterize the viraemia and viral excretion of Italian WNV L1 strains in pigeons. Thus we maintained pigeons alive for a period longer than the expected viraemic period. Second, birds were administered with a high dose of virus compared to previous studies whose challenge virus titres ranged from $10^{3} / \mathrm{ml}$ to $10^{5} / \mathrm{ml}$ p.f.u. This choice was made because a clear correlation has been demonstrated previously between the viral dose and the probability of becoming viraemic after inoculation or mosquito bite, which increases the proportion of inoculated birds that became viraemic in a dose-dependent manner [50]. Likewise, higher doses means more rapid onset of viraemia and oral shedding
[50, 51], although no significant differences among doses after 1-2 days, when peak viremia titres were reached, have been described [52]. Therefore, as for the limited number of pigeons and the need to obtain an absolute certainty of viraemia in the animals, pigeons were inoculated with a high dose of virus.

In conclusion, the pigeon has been demonstrated to be a competent reservoir host for Italian WNV L1 strains, thereby creating new scenarios regarding WNV surveillance and its importance for the public health system. The WHO has defined the prototypical amplifying host as a species that shows high levels of viraemia, is abundant in a given area and importantly, does not show any particular signs of disease. Based upon the results obtained from this study, such a definition is appropriate for the rock pigeon, since it developed infectious viraemia without showing clinical signs consistent with WNV infection. It seems that 'adaptation' has been developed between virus and its host and further studies are warranted in order to elucidate pigeon/WNV interaction at the molecular level. In this perspective, our study confirms the role pigeons may have in the monitoring of WNV transmission in the urban context as suggested by previous serosurveillance studies conducted in Greece. Seroconversion in pigeons was indeed recorded $<50$ days before the first human cases of disease [38].

\section{ACKNOWLEDGEMENTS}

Funding was provided by the Italian Ministry of Health. Mention of trade names or commercial products in this article is solely for the purpose of providing specific information and does not imply recommendation or endorsement by the OIE Reference Laboratory for West Nile Fever of Teramo. The authors are grateful to Vincenzo D'Innocenzo and Andrea Capobianco-Dondona for care and sampling of animals.

\section{DECLARATION OF INTEREST}

None.

\section{REFERENCES}

1. Smithburn K, et al. Neurotropic virus isolated from the blood of a native of Uganda. American Journal of Tropical Medicine and Hygiene 1940; 20: 471-492.

2. Colpitts TM, et al. West Nile Virus: biology, transmission, and human infection. Clinical Microbiology Reviews 2012; 25: 635-648. 
3. Kuno G, et al. Phylogeny of the genus Flavivirus. Journal of Virology 1998; 72: 73-83.

4. Poidinger M, et al. Molecular characterization of the Japanese encephalitis serocomplex of the Flavivirus genus. Journal of Virology 1996; 218: 417-421.

5. Berthet FX, et al. Extensive nucleotide changes and deletions within the envelope glycoprotein gene of Euro-African West Nile viruses. Journal of General Virology 1997; 78: 2293-2297.

6. Calistri P, et al. Epidemiology of West Nile in Europe and in the Mediterranean basin. Open Virology Journal 2010; 4: 29-37.

7. Charrel RN, et al. Evolutionary relationship between Old World West Nile virus strains. Evidence for viral gene flow between Africa, the Middle East, and Europe. Virology 2003; 315: 381-388.

8. Lanciotti RS, et al. Complete genome sequences and phylogenetic analysis of West Nile virus strains isolated from the United States, Europe, and the Middle East. Virology 2002; 298: 96-105.

9. Pachler K, et al. Putative new West Nile virus lineage in Uranotaenia unguiculata mosquitoes, Austria, 2013. Emerging Infectious Diseases 2014; 2012: 2119-2122.

10. Pérez-Ramírez E, et al. Experimental infections of wild birds with West Nile Virus. Viruses 2014; 6: 752-781.

11. Rizzoli A, et al. The challenge of West Nile virus in Europe: knowledge gaps and research priorities. Eurosurveillance 2015; 20: pii: 21135.

12. Anderson JF, et al. Isolation of West Nile virus from mosquitoes, crows, and a Cooper's hawk in Connecticut. Science 1999; 286: 2331-2333.

13. Gubler DJ. The continuing spread of West Nile virus in the western hemisphere. Clinical Infectious Diseases 2007; 45: 1039-1046.

14. Molaei G, et al. Host feeding patterns of Culex mosquitoes and West Nile virus transmission, northeastern United States. Emerging Infectious Diseases 2006; 12: 468-474.

15. Rappole JH, et al. Migratory birds and spread of West Nile virus in the Western Hemisphere. Emerging Infectious Diseases 2000; 6: 319-328.

16. Bowen RA, et al. Experimental infections with West Nile virus. Current Opinion in Infectious Diseases 2007; 20: 293-297.

17. Monaco F, et al. West Nile disease epidemic in Italy: first evidence of overwintering in Western Europe? Research in Veterinary Sciences 2009; 91: 321-326.

18. Monaco F, et al. Re-emergence of West Nile virus in Italy. Zoonoses Public Health 2010; 57: 476- 486.

19. Monaco F, et al. 2009 West Nile disease epidemic in Italy: first evidence of overwintering in Western Europe? Research in Veterinary Science 2011; 91: 321-326.

20. Savini G, et al. Phylogenetic analysis of West Nile virus isolated in Italy in 2008. Eurosurveillance 2008; 13: pii: 19048.

21. Monaco F, et al. The 2011 West Nile disease outbreak in Sardinia region, Italy. Veterinaria Italiana 2015; 51: 5-16.

22. Komar N. West Nile virus: epidemiology and ecology in North America. Advances in Virus Research 2003; 61: 185-234.
23. Shochat E, et al. From patterns to emerging processes in mechanistic urban ecology. Trends in Ecology \& Evolution 2006; 21: 186-191.

24. Sotelo E, et al. Phylogenetic relationships of Western Mediterranean West Nile virus strains (1996-2010) using full-length genome sequences: single or multiple introductions? Journal of General Virology 2011; 92: 2512-22.

25. Barzon L, et al. New endemic West Nile virus lineage 1a in northern Italy, July 2012. Eurosurveillance 2012; 17 pii: 20231

26. Eiden M, et al. Two new real-time quantitative reverse transcription polymerase chain reaction assays with unique target sites for the specific and sensitive detection of lineages 1 and 2 West Nile virus strains. Journal of Veterinary Diagnostic Investigation 2010; 22: 748-753.

27. Lanciotti RS, et al. Rapid detection of West Nile virus from human clinical specimens, field-collected mosquitoes, and avian samples by TaqMan reverse transcriptase-PCR assay. Journal of Clinical Microbiology 2000; 38: 4066-4071.

28. Di Gennaro A, et al. Serum-neutralization assay can efficiently replace plaque reduction neutralization test for detection and quantitation of West Nile virus antibodies in human and animal serum samples. Clinical and Vaccine Immunology 2014; 21: 1460-1462.

29. Reed LJ, Muench H. A simple method of estimating fifty percent endpoints. American Journal of Hygiene 1938; 27: 493-497.

30. Dulbecco R, et al. The nature of viruses. In: Dulbecco R, Ginsberg HS, eds. Virology. Philadelphia, USA: J. B. Lippincott Company, pp. 400-401.

31. Komar N, et al. Eastern equine encephalitis virus in birds: relative competence of European starlings (Sturnus vulgaris). American Journal Tropical Medicine Hygiene 1999; 60: 387-391.

32. Kilpatrick AM, et al. Ecology of West Nile virus transmission and its impact in the Western Hemisphere. Auk 2007; 124: 1121-1136.

33. Morabito S, et al. Detection and characterization of shiga-toxin producing Escherichia coli in feral pigeons. Veterinary Microbiology 2001; 82: 275-283.

34. Pedersen K, Clark L, Andelt WF, Salman MD. Prevalence of shiga toxin-producing Escherichia coli and Salmonella enterica in rock pigeons captured in Fort Collins, Colorado. Journal of Wildlife Diseases 2006; 42: 46-55.

35. Abulreesh HH. Free living rock pigeon (Columba livia) as an environmental reservoir of enteric bacterial pathogens resistant to antimicrobial drugs in Saudi Arabia. Current Research in Bacteriology 2011; 4: 28-33.

36. Llopis-Victoriano, et al. Further circulation of West Nile and Usutu viruses in wild birds in Italy. Infection Genetics and Evolution 2015; 32: 292-297.

37. Allison AB, et al. West Nile virus viremia in wild rock pigeons. Emerging Infectious Diseases Journal 2004; 10: $2252-2255$.

38. Chaintoutis SC, et al. Evaluation of a West Nile virus surveillance and early warning system in Greece, 
based on domestic pigeons. Comparative Immunology, Microbiology and Infectious Diseases 2014; 37: 131-141.

39. Komar N, et al. Experimental infection of North American birds with the New York 1999 strain of West Nile virus. Emerging Infectious Diseases Journal 2003; 9: 311-322.

40. Malkinson M, et al. Introduction of West Nile virus in the Middle East by migrating White Storks. Emerging Infectious Diseases Journal 2002; 8: 392-397.

41. Panella NA, Young G, Komar N. Experimental infection of Eurasian collared-dove (Streptopelia decaocto) with West Nile virus. Journal of Vector Ecology 2013; 38: 210-214.

42. Deubel V, et al. Variations in biological features of West Nile virus. Annals of the New York Academy of Sciences 2001; 951: 195-206.

43. Schneider BS, et al. Potentiation of West Nile encephalitis by mosquito feeding. Viral Immunology 2006; 19: $74-82$

44. Schneider BS, et al. Aedes aegypti saliva alters leukocyte recruitment and cytokine signaling by antigenpresenting cells during West Nile Virus Infection. PLOS ONE 2010; 5: e11704.

45. Styer LM, et al. Mosquito saliva causes enhancement of West Nile virus infection in mice. Journal of Virology 2011; 85: 1517-1527.
46. Guerrero-Sanchez S, et al. West Nile virus infection of birds, Mexico. Emerging Infectious Diseases 2001; 17: 2245-2252.

47. Del Amo J, et al. Experimental infection of house sparrows (Passer domesticus) with West Nile virus isolates of Euro-Mediterranean and North American origins. Veterinary research 2014; 45: 33-41.

48. Goddard LB, et al. Vector competence of California mosquitoes for West Nile virus. Emerging Infectious Diseases 2002; 8: 1385-1391.

49. Sotelo E, et al. Pathogenicity of two recent Western Mediterranean West Nile virus isolates in a wild bird species indigenous to Southern Europe: the red-legged partridge. Veterinary Research 2011; 42: 11.

50. VanDalen KK, et al. West Nile virus infection in American robins: new insights on dose response. PLoS ONE 2013; 8: e68537.

51. Oesterle PT, et al. Experimental infection of Cliff swallows (Petrochelidon pyrrhonota) with varying doses of West Nile virus. American Journal of Tropical Medicine Hygiene 2009; 81: 1159-1164.

52. Reisen WK, et al. Avian host and mosquito (Diptera: Culicidae) vector competence determines the efficiency of West Nile and St. Louis encephalitis virus transmission. Journal of Medical Entomology 2005; 42: 367-375. 